\title{
Demographics Associated with Autistic Spectrum Diagnosis in England
}

\author{
Mischa N.C. Mockett \\ Central Manchester University Hospitals NHS Foundation Trust \\ Manchester, United Kingdom \\ Lydia Kinton \\ Manchester Medical School \\ Manchester, United Kingdom \\ Louise J. Theodosiou \\ Central Manchester University Hospitals NHS Foundation Trust \\ Powerhouse, 140 Raby St, M14 4ST, Manchester, United Kingdom \\ Tel: 44-161-22-67-457 E-mail: louise.theodosiou@cmft.nhs.uk
}

Received: February 16, 2012 Accepted: March 29, $2012 \quad$ Published: June 1, 2012

doi:10.5539/res.v4n2p18

URL: http://dx.doi.org/10.5539/res.v4n2p18

\begin{abstract}
There is a growing body of work elucidating the demographics surrounding autistic spectrum disorders. This study sought to develop the local evidence base, enhance the awareness of educationalists in north Manchester and test the hypothesis that young people from all cultural groups are able to access the mental health service. The Social Communication Assessment and Intervention Team in the North Manchester Child and Adolescent Mental Health Service received 89 referrals of children with suspected autism between April 2010 and June 2011. Information was available about 69 cases. Some cases are still in the process of assessment while 20 children and young adults have received a diagnoses of autistic spectrum disorders; 4 African Caribbean, 11 White British, 3 Pakistani, 1 dual heritage and 1 did not complete the form. Further demographics and implications for training are discussed.
\end{abstract}

Keywords: Autistic spectrum disorders, Access to services

\section{Introduction}

1.1 Introducing autistic spectrum disorders

Autistic Spectrum Disorders (ASD) are pervasive developmental disorders characterised by a triad of impairments that manifest before 3 years of age. The impairments include social deficits, communication deficits and restricted/repetitive interests and behaviours. It is common condition that affects at least 60 children per 10,000 (Coghill et al 2009). Prevalence is rising. In 1979 the National Autistic Society (NAS) estimated that there were 39 cases per 10,000. By 1993 this had risen to 91 per 10,000 while more recently Baird et al (2006) suggested that rates for all autistic disorders combined may be 116.1 per 10,000.

\subsection{Why are autistic spectrum disorders important}

Public consciousness of ASD has been expanding at almost the same rate as the evidence base. Within the UK, the NAS has become an important lobbying tool, and it is of note that the proposed standards in the Diagnostic and Statistical Manual of Mental Disorders (DSM-5) acknowledge the lifespan implications of this important developmental condition. Considerable progress has also been made in developing screening tools, and in raising awareness amongst the general public and also the universal services that work with children and young people, 
such as education services and primary healthcare providers. Within the United Kingdom, children's services now offer a service to children up to 18 years old, further enhancing rates of diagnosis and support for vulnerable young people.

The aetiology of ASD is yet to be fully elucidated; presently all that can be stated definitively is that there is a clear genetic component. Furthermore, the factors which lead to affected children to present to services are also complex; times of stress and increased demands such as transition from primary to secondary school, or transition to college education are often triggers. In the United Kingdom college attendance is often the first time that adolescents can choose their own clothes, furthermore social groups are often redistributed as colleges specialise in sciences or arts. High functioning young people with social communication disorders can often struggle with this process, and need to be supported through the challenging task of accepting that they have lifespan diagnosis.

The North Manchester Social Communication and Intervention Team (SCAIT) are the multidisciplinary team of mental health care professionals who initiate the communication with and assessment of new patients. Patients are referred to the SCAIT team by many people. It may be the community paediatrician, school, the general practitioner or any professional who suspects a child or young person of having social or communicational difficulties. Out of 354 geographical districts in England, Manchester is the second most deprived, furthermore, north Manchester has a high number of children. Thus this area represents a particularly vulnerable population.

The SCAIT team put in to the practise the guidelines laid out by the National Autism Plan for Children (NAPC). These guidelines address identification, diagnosis and access to early intervention for pre-school and primary school. They also emphasise the importance of a multi-disciplinary approach to treatment to deliver gold standard care.

Social demographics play a large part in assessing the patient as a whole, as demonstrated by the Youth Justice Board study 'Differences or Discrimination'. This study focused on finding out whether differences in outcome related to ethnicity or gender were justifiable in terms of case-related or other legitimate factors, or where there was evidence of discrimination. It showed that the chances of a case involving a dual heritage young male being prosecuted were 2.7 times that of a white young male with similar characteristics. With respect to health care and North Manchester being such a diverse area of people, with many different social situations and varying demographics, it is important that the service that North Manchester CAHMS is easily and readily accessible to all.

\subsection{Hypothesis}

Recent cultural awareness raising initiatives within Manchester have enabled all ethnic groups to achieve equal access to specialist autism assessments.

\section{Method}

\subsection{Sample}

Data was collected from the files of all the patients referred to North Manchester SCAIT between April 2010 and June 2011.

\subsection{Measure}

Demographic information was collected using a tick box form with the following headings: Age at the time of referral; ethnic origin; gender; school attended, possible learning difficulties; languages spoken (first language); housing situation; number of primary carers; number of siblings; evidence of substance misuse; youth justice involvement and referring agency. Both patients who have a diagnosis and are awaiting a diagnosis were included in this sample. This ensured that there were 89 patients eligible for inclusion, the authors were able to locate 69 sets of case notes. Data was entered into and analysed using the statistical package SPSS version 10.

\section{Results}

\subsection{Statistics and data analysis}

\subsubsection{Ethnicity}

Only 1 family of the 69 did not provide this information, 45 were White British, comprising $65.2 \%$ of the sample. The next most represented ethnicity was Pakistani, being $10.1 \%$ of the sample (Table 1 ).

The majority of referrals were White British patients which is consistent with the population in North Manchester. However White British patients were slightly under-represented and interestingly there were no patients from a Bangladeshi, Irish or Chinese origin in this sample which are populations that are well 
represented in the Manchester population. On the other hand, the Pakistani population were the most over represented in the sample.

\subsubsection{Gender}

Of the 69 patients used for the study, 57 of the patients referred to SCAIT in this time were male.

Education Status

Learning difficulties could be a differential diagnosis for ASD, and can impact on the presentation of symptoms. In the sample, 24 patients had delayed milestones and 23 had formal diagnoses of learning difficulties. As autistic spectrum disorders can present with motor and cognitive delay, the patients who are said to be 'delayed' are not formally diagnosed until the two diagnoses can be separated. Notably, 16 of the White British patients had delayed milestones and 15 of the patients had diagnoses learning difficulties. Conversely, 4 of the patients were said to be more advanced than expected for their age.

The Pakistani population demonstrated more learning difficulties than other communities.

\subsubsection{Language}

The main language spoken by patients referred to SCAIT is English.

\subsubsection{Home life}

The patient's living circumstances were examined, including number of parents at home, how many siblings they have and what type of accommodation they live in. The results demonstrate that in patients referred to SCAIT, it is more common to live in a 2 parent household than a 1 parent household. The only ethnic population which differs is the Polish community, however this is only a one patient sample. Furthermore, 65 of the patients lived in a house, 3 in flats and 1 in a bungalow indicating all of the patients were suitably housed.

\subsubsection{Referring bodies}

There have been an equal number of referrals from the Psychology team and the Community Paediatricians. Interestingly the Community Paediatricians refer the most patients across all ethnicities. Finally, of the 69 patients, 22 patients received a diagnosis of ASD and some cases were still ongoing and only 1 case was closed. None of the patients included in this audit had any history of substance misuse or involvement with Youth Justice.

\section{Discussion}

The authors are aware that simply examining the ethnicity and superficial demographics of a small sample, does not allow for a clear perspective on the referral patterns. Furthermore, subtleties such as the representation of second generation traveller communities remain unresolved. Broadly speaking, White British population are on average under-represented. While some ethnic minority groups living in the area are over-represented. This suggests that vulnerable minority communities are able to access the key mental health resource. It is interesting to note that the White British proportion is very similar to the findings of the previous audit (Mockett et al, 2011) in which $64.5 \%$ were White British. The authors note that community paediatrics referred higher numbers of patients from ethnic minorities than psychology services. One hypothesis could be that in their role of offering a universal service to all school age children, they are able to engage families from all backgrounds. Anecdotal feedback from families suggests that at times, mental heath services can be perceived as stigmatizing; paediatric services can provide a valuable bridge to important diagnostic routes for some families. Furthermore, this may suggest that universal services such as general practitioners need repeated training regarding this developmental condition.

The strong associated between learning disability and autistic spectrum disorders has been repeatedly referenced. In the present sample 24 children had delayed milestones and 23 had diagnoses of learning difficulties, suggesting over half of the sample has some sort of developmental delay. There is no evidence to suggest that autism may be over-represented in this sample when compared to aspergers syndrome. However it is of note that anecdotal evidence from elsewhere in the wider service suggests that bright girls with Aspergers Syndrome are picked up later. This emphasises the need for ongoing training to target both schools which work children up to 16 and colleges serving $17-18$ year olds.

With respect to home life and access to family support, the study suggests most patients in the study have a 2 parent household and secure housing. This creates ideas for future research in that it would be useful to know whether the referrals were from one particular socio-economic class. The diverse range of backgrounds and presenting histories of patients that are referred to the SCAIT clinic in North Manchester, could indicate that the 
mental health service is accessible for all.

North Manchester is an ethnically diverse area so it is becoming of increasing importance to ensure that barriers to consultation and communication are avoided. This study suggests that the ethnic minority population in north Manchester is growing. It may be helpful for the north Manchester CAMHS to develop links with local community leaders to ensure that the service offered meets the needs and expectations of this vulnerable population.

Finally the process of audit raises awareness within teams about the need to maintain clinical governance standards and ensure all appropriate cases are referred to specialist teams. The clinicians involved plan to repeat the audit in the next year.

\section{References}

Allington, S. P. (2006). Mental health of children with learning disabilities. Advances in Psychiatric Treatment, 12,130-138.

Baird, G., Simonoff, E., Pickles, A., Chandler, S., Loucas, T., Meldrum, D., \& Charman, T. (2006). Prevalence of disorders of the autism spectrum in a population cohort of children in South Thames: the Special Needs and Autism Project (SNAP). Lancet, 368(9531), 210-215.

Coghill, D. (2009). Child and Adolescent Psychiatry (pp. 126-141). Oxford University: Oxford University Press. Diagnostic and Statistical Manual of Mental Disorders (DSM-5). [Online] Available: http://www.dsm5.org/Page s/Default.aspx

Green, H., McGinnity, A., Meltzer, H., Ford, T., \& Goodman, R. (2004). Mental health of children and young people in Great Britain. Office for National Statistics.

Mockett, M., Hawke, E., \& Theodosiou, L. (2011). Ethnic composition of children referred into North Manchester SCAIT with suspected ASD. Procedia, social and behavioral sciences, (30).

National Initiative for Autism: Screening and Assessment. (2003). National Autism Plan for Children Guildlines (NAPC). [Online] Available: http://www.rcpsych.ac.uk/PDF/NAExecSum.pdf

Rogers, S. (2011). The ethnic population of England and Wales broken down by local authority. [Online] Available:

(August 6, 2011)

Youth Justice Board. (2004). Differences or Discrimination?. [Online] Available: http://www.yjb.gov.uk/publicat ions/Resources/Downloads/Differences\%20or\%20Discrimination\%20-\%20Summary.pdf

Table 1. Ethnicity of patients referred to SCAIT compared to the Manchester population

\begin{tabular}{lccc}
\hline \multicolumn{1}{c}{ Ethnicity } & $\begin{array}{c}\text { \% of Manchester } \\
\text { population }\end{array}$ & $\begin{array}{c}\text { \% of patients } \\
\text { referred into SCAIT }\end{array}$ & $\begin{array}{c}\text { Difference between SCAIT and } \\
\text { Manchester population }\end{array}$ \\
\hline White British & 69.9 & 65.2 & -4.7 \\
Black African & 2.5 & 7.2 & 4.7 \\
Black Caribbean & 1.8 & 2.9 & 1.1 \\
Indian & 3.4 & 4.3 & 0.9 \\
Pakistani & 5.2 & 10.1 & 4.9 \\
White \& Black & 1.1 & 4.3 & 3.2 \\
Caribbean & & 1.4 & 0.9 \\
White \& Black & 0.5 & 4.6 & -11.1 \\
African & 15.7 & & \\
Other & & & \\
\hline
\end{tabular}

